\title{
INDICADORES PARA ANÁLISE DE ESPAÇOS LIVRES: ENFOQUE EM PROTEÇÃO E SEGURANÇA
}

VISBQP

UBERLÂNDIA 2019

\author{
WOLKART, Isabella \\ Universidade Federal do Espírito Santo, e-mail: isabellawolkarł@gmail.com \\ KOFFER, Amanda Lovatti \\ Universidade Federal do Espírito Santo, e-mail: lovatti.amanda@gmail.com \\ CONDE, Karla Moreira \\ Universidade Federal do Espírito Santo, e-mail: karla.conde@ufes.br \\ JESUS, Luciana Aparecida Netto \\ Universidade Federal do Espírito Santo, e-mail: luciana.njesus@gmail.com \\ RAMOS, Larissa Letícia Andara \\ Universidade Vila Velha, e-mail: Larissa.ramos@uvv.br
}

\begin{abstract}
RESUMO
O presente artigo é parte integrante da pesquisa intitulada "Identificação de áreas de convívio público e áreas verdes do município de Vitória-ES", desenvolvida em parceria entre duas universidades do Espírito Santo. O estudo analisa a qualidade de praças dos municípios de Vitória e Vila Velha-ES, tendo como base indicadores selecionados e adaptados do Índice de Caminhabilidade (iCam). Para tal, as áreas verdes e espaços livres de uso público de regiões administrativas dos dois municípios foram identificados e classificados. Foram selecionados indicadores do Índice de Caminhabilidade (iCam) elaborado pelo Instituto de Políticas de Transporte \& Desenvolvimento (ITDP Brasil), considerando as adaptações necessárias para a aplicação em praças, e incluídos outros indicadores julgados necessários pelo grupo de pesquisa, totalizando 36 indicadores, subdivididos em 11 atributos e 4 categorias, que são: Proteção e segurança; Conforto e imagem; Acessos e conexões; e Sociabilidade, uso e atividades. Este artigo apresenta os resultados da aplicação dos indicadores da categoria "Proteção e Segurança" na Regional 9 - Jardim da Penha/Vitória-ES, composta por 6 bairros. Com parâmetro de classificação por pontuação de 0 a 3, "insuficiente" a "ótimo". A maioria das praças obteve resultados "bom" na média de indicadores do ITDP e "suficiente" na média geral. Os indicadores "Eficiência energética", "Câmera" e "Material dos brinquedos" foram os principais responsáveis por essa diferença. Observa-se a necessidade de aplicação dos indicadores das demais categorias para uma avaliação mais abrangente.
\end{abstract}

Palavras-chave: Áreas verdes, Espaços livres, Indicadores, Praças.

\begin{abstract}
This paper is a part of the research entitled "Identification of public living areas and green areas of the municipality of Vitória-ES", developed in partnership between two universities of Espírito Santo. The study analyzes the quality of squares of the municipalities of Vitoria and Vila Velha-ES, based on selected indicators and adapted from the Walkability Index (iCam). To this end, the green areas and open spaces of public use of administrative regions of the two municipalities were identified and classified. The indicators used by the research were selected from the Walkability Index (iCam), developed by the Institute of Transportation and Development Policies (ITDP Brasil), considering the adaptations necessary for the application in squares and included other indicators deemed necessary by the research group, totaling 36 indicators, subdivided into 11 attributes and 4 categories, which are: Protection and security; Comfort and image; Access and connections; and Sociability, use and activities. This article presents the results of the application of the indicators of the category "Protection and Security" in Regional 9 - Jardim da
\end{abstract}

WOLKART, I.; KOFFER, A. L.; CONDE, K. M.; JESUS, L. A. N.; RAMOS, L. L. A: Indicadores para análise de espaços livres: enfoque em proteção e segurança. In: SIMPÓSIO BRASILEIRO DE QUALIDADE DO PROJETO NO AMBIENTE CONSTRUÍDO, 6., 2019, Uberlândia. Anais... Uberlândia: PPGAU/FAUED/UFU, 2019. p. 460-473. DOI https://doi.org/10.14393/sbqp19045. 
Penha/Vitória-ES. With scoring parameter from 0 to 3, "insufficient" to "optimal". Most of the squares had "good" results in average ITDP indicators and "sufficient" in the overall average. The indicators "Energy Efficiency", "Camera" and "Toy material" were mainly responsible for this difference. It is observed the need to apply the indicators of the other categories for a more comprehensive evaluation.

Keywords: Green Areas, Open Spaces, Indicators, Squares.

\section{INTRODUÇÃO}

As áreas verdes e os espaços livres são fronteiras do traçado urbano que visam à salubridade do meio (MEIRELLES, 2007 apud FERREIRA; PAULA, 2014), destinados a todo tipo de utilização que se relacione com caminhadas, descanso, práticas de esporte e, em geral, à recreação e ao entretenimento (CAVALHEIRO, F. et al., 1999).

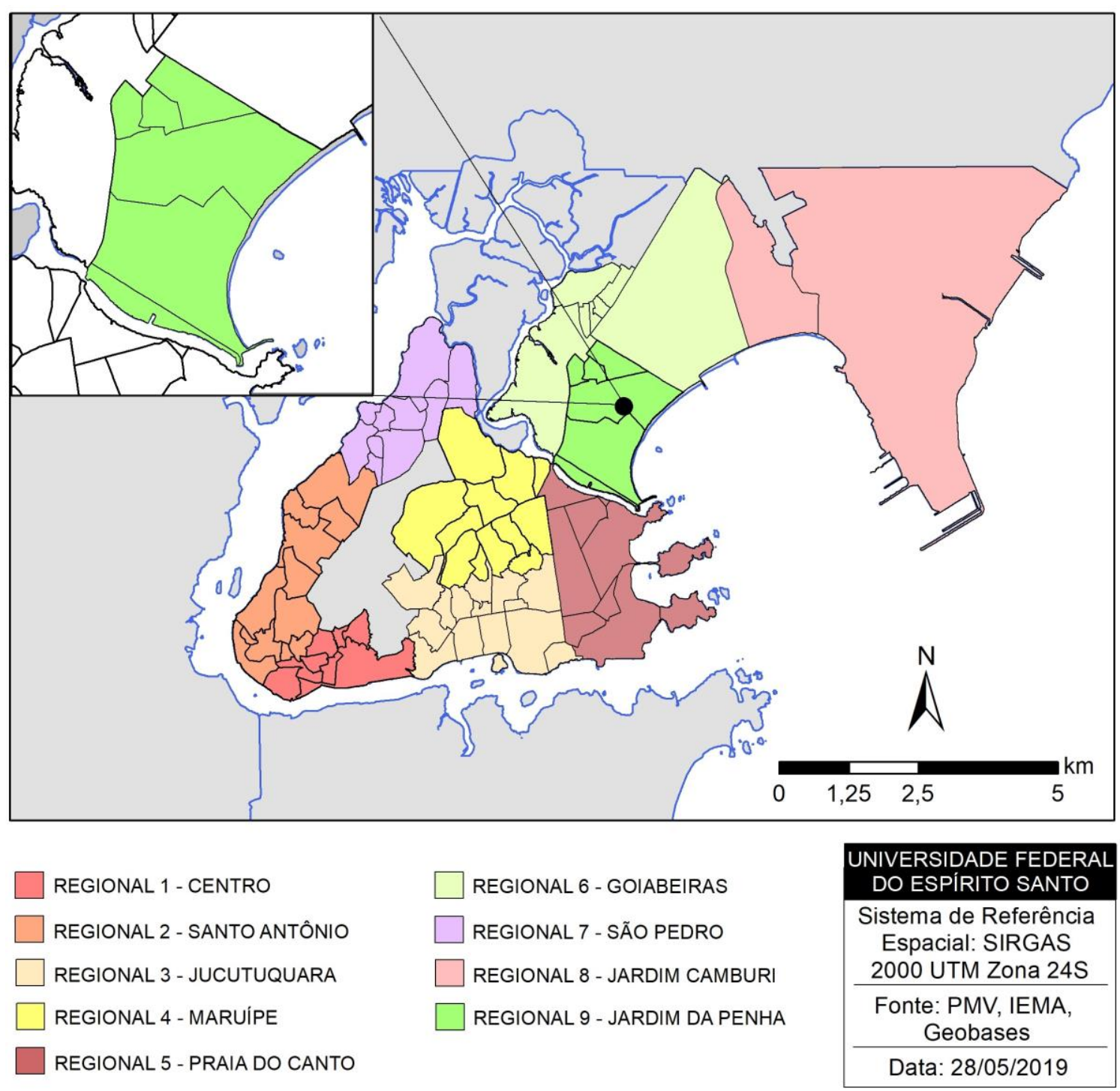

Figura 1 - Mapa das Regionais de Vitória (ES) Fonte: Autor (2019)

Em pesquisa intitulada "Identificação de áreas de convívio público e áreas verdes do município de Vitória (ES)", desenvolvida pela Universidade Federal do Espírito Santo (UFES), em parceria com o grupo de pesquisa "Paisagem Urbana e Inclusão" da Universidade Vila Velha (UVV) foram selecionados, 
adaptados e desenvolvidos indicadores para avaliação de praças, tendo como referência o Índice de Caminhabilidade (iCam) (ITDP, 2018). Os indicadores foram organizados em "categorias", como no iCam, e subdivididos em "atributos" pelo grupo de pesquisa.

Este artigo apresenta a avaliação da qualidade de praças da Regional 9 Jardim da Penha, Vitória - ES, por meio de indicadores que abrangem o tema "Proteção e Segurança".

A cidade de Vitória, capital do Espírito Santo, possui $96,536 \mathrm{~km}^{2}$, aproximadamente 358.267 habitantes (IBGE, 2010) e divide-se em nove Regiões Administrativas, conforme Lei Municipal n 8.61 1/2014, são: Regional 1 Centro, Regional 2 - Santo Antônio, Regional 3 - Jucutuquara, Regional 4 Maruípe, Regional 5 - Praia do Canto, Regional 6 - Goiabeiras, Regional 7 - São Pedro, Regional 8 - Jardim Camburi e Regional 9 - Jardim da Penha. A Figura 1 apresenta as nove Regionais do município de Vitória-ES e destaca a Regional 9. parte continental do município e região de análise.

\section{CONCEITUAÇÃO}

Magnoli (1982) afirma que os espaços livres de edificação ou de urbanização podem ser identificados como espaços abertos, públicos ou privados. As áreas verdes são um tipo especial de espaços livres onde o elemento fundamental de composição é a vegetação. Elas devem satisfazer três objetivos principais: ecológico-ambiental, estético e de lazer (CAVALHEIRO, 1999).

Os espaços livres podem ser classificados segundo suas tipologias (particulares, potencialmente coletivos e públicos) e suas categorias (área verde, parque urbano, praça, arborização urbana, entre outros) (BUCCHERI FILHO; NUCCl, 2006).

As áreas livres, no contexto urbano, segundo Lima (1999), desempenham função ecológico-ambiental, estética, paisagística, climática, de defesa, psicológica e, também, recreativa e de lazer. $E$ as áreas verdes, especificamente, oferecem benefícios, como a composição atmosférica, equilíbrio do solo, clima e da polvição (BOVO e AMORIM, 2009).

Para avaliação de espaços livres e áreas verdes, são fundamentais indicadores que mensurem as condições de caminhabilidade, pois estão relacionados a riscos de colisões e fatalidades, e a segurança pública (ITDP, 2018).

Uma das primeiras a levantar a discussão da segurança nos espaços públicos, Jane Jacobs (1961), afirma que a ordem pública - a paz nas calçadas e nas ruas - não é mantida basicamente pela polícia, sem com isso negar sua necessidade, mas é mantida fundamentalmente pela rede intrincada, quase inconsciente, de controles e padrões de comportamento espontâneos presentes em meio ao próprio povo e por ele aplicados.

\section{METODOLOGIA}

Com base no levantamento teórico, foi definida a forma de avaliação do objeto de análise, as praças. A ferramenta base para a avaliação foi o Índice de Caminhabilidade (iCam), desenvolvido pelo Instituto de Políticas de Transporte e Desenvolvimento - ITDP Brasil, cujos indicadores foram elaborados 
para a avaliação de vias. Para adequar a ferramenta ao objeto de análise, foram realizados estudos e discussões com o auxílio do Guia do espaço público para inspirar e transformar (HEEMANN; SANTIAGO, 2015).

O iCam define duas unidades básicas para a coleta de dados, que são as "categorias" e os "indicadores". As "categorias" são utilizadas como parâmetros centrais de referência para a avaliação, definindo a distribuição da pontuação (ITDP, 2018). As categorias apresentadas no iCam foram renomeadas neste trabalho como "atributos" e organizadas com base no Guia do espaço público, em categorias, atributos e indicadores.

As "categorias" são consideradas como o conjunto de critérios utilizados para avaliar um determinado assunto, tema ou objeto; os "atributos", termo que qualifica as categorias; e os "indicadores" avaliam, de forma unitária, o desempenho do objeto analisado (CONDE et al., 2019). Após seleção e adaptação, os 36 indicadores foram organizados em 4 categorias: Proteção e Segurança, Conforto e Imagem, Acessos e Conexões e Sociabilidade Usos e Atividades, subdivididas em 11 atributos. O Quadro 1 apresenta as categorias, atributos e indicadores para avaliação de praças e em cinza estão destacados os indicadores adaptados do ITDP.

Ainda com base no índice de Caminhabilidade - iCam (ITDP, 2018), foram estabelecidas pontuações, de 0 a 3, que qualificam a praça em: ótimo, bom, suficiente e insuficiente, em que cada pontuação equivale a um parâmetro de qualidade específico para cada indicador (Quadro 2).

Paralelamente à seleção de indicadores e o estabelecimento dos parâmetros para avaliação, foi utilizado o Sistema Informativo Geográfico (SIG) no software ArcGis para mapear os espaços livres de uso público. Foram identificados, com base no mapeamento realizado pela Prefeitura de Municipal de Vitória (PMV), todos os espaços livres de uso público da Regional 9 - Jardim da Penha e distinguidos os parques urbanos, a orla da Praia de Camburi e as praças, este último para análise.

Foram considerados praças os espaços livres de uso público maiores do que $450 \mathrm{~m}^{2}$ (BUCCHERI FILHO; NUCCl, 2006), e que apresentam um ou mais equipamentos fixos para realização de atividades relacionadas ao lazer. Definiu-se, os raios de influência dos parques e praças, sendo de 1.000 metros (KLIASS, 1993) e 400 metros (HANNES, 2016) respectivamente.

\begin{tabular}{|c|c|c|}
\hline \multicolumn{3}{|c|}{ Quadro 1 - Categoria, atributos e indicadores } \\
\hline Categoria & Atributo & Indicador \\
\hline \multirow{10}{*}{$\begin{array}{c}\text { A. Proteção e } \\
\text { Segurança }\end{array}$} & \multirow{2}{*}{ A.1. Segurança Viária } & A.1.1. Travessias \\
\hline & & A.1.2. Tipologia da Rua \\
\hline & \multirow{4}{*}{ A.2. Segurança Pública } & A.2.1. Iluminação \\
\hline & & A.2.2. Eficiência Energética \\
\hline & & A.2.3. Fluxo de Pedestres Diurno e Noturno \\
\hline & & A.2.4. Câmeras de Segurança \\
\hline & \multirow{4}{*}{ A.3. Proteção Física } & A.3.1. Localização do Espaço para Brincar \\
\hline & & A.3.2. Material do Piso da Área Infantil \\
\hline & & A.3.3. Material dos Brinquedos Infantis \\
\hline & & A.3.4. Estado de Conservação dos Brinquedos \\
\hline
\end{tabular}




\begin{tabular}{|c|c|c|}
\hline \multirow{8}{*}{$\begin{array}{l}\text { B. Conforto e } \\
\text { Imagem }\end{array}$} & \multirow{4}{*}{ B.1. Ambiente } & B.1.1. Coleta de Lixo \\
\hline & & B.1.2. Polvição Sonora \\
\hline & & B.1.3. Sombra e Abrigo \\
\hline & & B.1.4. Sombra e Abrigo em Área Específica \\
\hline & \multirow{3}{*}{$\begin{array}{l}\text { B.2. Áreas Verdes/ } \\
\text { Cobertura Vegetal }\end{array}$} & B.2.1. Área de Sombra de Copa de Árvore \\
\hline & & $\begin{array}{c}\text { B.2.2. Área de Sombra de Copa de Árvore em Área } \\
\text { Específica }\end{array}$ \\
\hline & & B.2.3. Cobertura Vegetal \\
\hline & $\begin{array}{l}\text { B.3. Espaços para } \\
\text { Sentar }\end{array}$ & B.3.1. Assentos \\
\hline \multirow{6}{*}{$\begin{array}{c}\text { C. Acessos e } \\
\text { Conexões }\end{array}$} & \multirow{3}{*}{ C.1. Mobilidade } & C.1.1. Dimensão das Quadras \\
\hline & & C.1.2. Distância a Pé ao Transporte Público \\
\hline & & C.1.3. Paraciclo/ Bicicletário \\
\hline & \multirow{3}{*}{$\begin{array}{l}\text { C.2. Calçada e } \\
\text { Pavimentação }\end{array}$} & C.2.1. Largura da Calçada \\
\hline & & C.2.2. Pavimentação da Calçada \\
\hline & & C.2.3. Pavimentação da Praça \\
\hline \multirow{10}{*}{$\begin{array}{c}\text { D. } \\
\text { Sociabilidade, } \\
\text { Usos e } \\
\text { Atividades }\end{array}$} & \multirow{4}{*}{ D.1. Atração } & D.1.1. Fachadas Fisicamente Permeáveis \\
\hline & & D.1.2. Fachadas Visualmente Ativas \\
\hline & & D.1.3. Uso Noturno e Diurno \\
\hline & & D. 1.4. Uso Misto \\
\hline & \multirow{3}{*}{$\begin{array}{l}\text { D.2. Equipamentos e } \\
\text { Atividades }\end{array}$} & D.2.1. Equipamentos Fixos e Serviços \\
\hline & & $\begin{array}{l}\text { D.2.2. Apropriações Comunitárias (identidade } \\
\text { sociocultural) }\end{array}$ \\
\hline & & D.2.3. Atividades que Incluem Idosos \\
\hline & \multirow{3}{*}{$\begin{array}{l}\text { D.3. Estímulos Motores e } \\
\text { Sensoriais }\end{array}$} & D.3.1. Estímulos Motores \\
\hline & & D.3.2. Estímulos Sensoriais/ Lúdicos \\
\hline & & D.3.3. Brincadeiras de Regras \\
\hline
\end{tabular}

Quadro 2 - Pontuações dos indicadores

\begin{tabular}{|c|c|c|c|}
\hline Pontuação 3 & Pontuação 2 a 2,9 & Pontuação 1 a 1,9 & Pontuação 0 a 0,9 \\
\hline Ótimo & Bom & Suficiente & Insuficiente \\
\hline
\end{tabular}

Fonte: Autor (2019)

Para aplicar os indicadores foram realizadas visitas a campo, e cada praça recebeu uma pontuação específica para cada indicador. A pontuação final foi definida pela média aritmética de todos os indicadores da categoria. O resultado qualifica a praça e permite compará-las.

Este artigo apresenta os resultados da aplicação e análise dos indicadores da categoria Proteção e Segurança nas praças da Regional 9 - Jardim da Penha, Vitória (ES).

\section{CATEGORIA PROTEÇÃO E SEGURANÇA}

O grupo de pesquisa qualificou a categoria Proteção e Segurança em três atributos "Segurança Viária", "Segurança Pública" e "Proteção Física", somando ao todo 10 indicadores. "Segurança Viária" e "Segurança Pública" 
compreendem categorias no iCam (ITDP, 2018), entretanto, nesta pesquisa, foram adaptadas para atributos. O atributo "Proteção Física" foi inserido pelo grupo de pesquisa a partir de um estudo sobre espaços para brincar realizado na Universidade Vila Velha (ES).

A categoria Proteção e Segurança avalia, por meio do atributo "Segurança Viária", a segurança do pedestre em relação ao tráfego de veículos motorizados e as condições de acesso às quadras imediatas, a partir de requisitos de conforto e acessibilidade universal. Este atributo apresenta dois indicadores adaptados do iCam (ITDP, 2018), que são: Travessias e Tipologia da rua.

Por meio do atributo "Segurança Pública" é avaliado a sensação de segurança do pedestre a partir do movimento existente na praça e do monitoramento público. Este atributo contempla quatro indicadores, dois adaptados do iCam (ITDP, 2018): lluminação e Fluxo de Pedestre Diurno e Noturno, e dois acrescentados pelo grupo de pesquisa, que são: Eficiência Energética e Câmeras de Segurança.

O atributo "Proteção Física" avalia as condições e a materialidade dos espaços destinados às crianças, prezando pelo conforto e segurança destas. O grupo de pesquisa inseriu quatro indicadores para a avaliação deste atributo, que são: Localização do espaço para brincar, Material do piso da área infantil, Material dos brinquedos infantis e Estado de conservação dos brinquedos.

Em campo, com o auxílio do software ArcGis® e das informações disponibilizadas online pela Prefeitura de Vitória, foi aferido o resultado de cada indicador, onde quatro parâmetros distintos justificam a pontuação de 0 a 3. O Quadro 3 apresenta os parâmetros da categoria Proteção e Segurança.

Quadro 3 - Parâmetros dos indicadores

\begin{tabular}{|c|c|c|c|c|c|}
\hline Atributo & Indicador & Pontuação 3 & $\begin{array}{c}\text { Pontuação de } 2 \\
\text { a } 2,9\end{array}$ & $\begin{array}{c}\text { Pontuação de } 1 \\
\text { a } 1,9\end{array}$ & $\begin{array}{c}\text { Pontuação de } 0 \\
\text { a } 0,9\end{array}$ \\
\hline \multirow{3}{*}{$\begin{array}{l}\text { A.l. } \\
\text { Segurança } \\
\text { Viária }\end{array}$} & $\begin{array}{l}\text { A.1.1. } \\
\text { Travessias }\end{array}$ & $\begin{array}{l}100 \% \text { das } \\
\text { travessias } \\
\text { cumprem os } \\
\text { requisitos de } \\
\text { qualidade }\end{array}$ & $\begin{array}{l}\geq 75 \% \text { das } \\
\text { travessias } \\
\text { cumprem os } \\
\text { requisitos de } \\
\text { qualidade }\end{array}$ & $\begin{array}{l}\geq 50 \% \text { das } \\
\text { travessias } \\
\text { cumprem os } \\
\text { requisitos de } \\
\text { qualidade }\end{array}$ & $\begin{array}{l}<50 \% \text { das } \\
\text { travessias } \\
\text { cumprem os } \\
\text { requisitos de } \\
\text { qualidade }\end{array}$ \\
\hline & \multirow{2}{*}{$\begin{array}{l}\text { A.1.2. Tipologia } \\
\text { da Rua }\end{array}$} & \multirow{2}{*}{$\begin{array}{c}\text { Vias exclusivas } \\
\text { para pedestres } \\
\text { (calçadões) }\end{array}$} & \begin{tabular}{|c} 
Vias \\
compartilhadas \\
. Velocidade $\leq$ \\
$20 \mathrm{~km} / \mathrm{h}$
\end{tabular} & \begin{tabular}{|c|} 
Vias \\
compartilhadas \\
. Velocidade $\leq$ \\
$30 \mathrm{~km} / \mathrm{h}$
\end{tabular} & $\begin{array}{c}\text { Vias } \\
\text { compartilhadas } \\
\text {. Velocidade > } \\
30 \mathrm{~km} / \mathrm{h}\end{array}$ \\
\hline & & & $\begin{array}{c}\text { Vias com } \\
\text { calçadas } \\
\text { segregadas. } \\
\text { Velocidade } \\
30 \mathrm{~km} / \mathrm{h}\end{array}$ & $\begin{array}{c}\text { Vias com } \\
\text { calçadas } \\
\text { segregadas. } \\
\text { Velocidade } \leq \\
50 \mathrm{~km} / \mathrm{h}\end{array}$ & $\begin{array}{c}\text { Vias com } \\
\text { calçadas } \\
\text { segregadas. } \\
\text { Velocidade > } \\
50 \mathrm{~km} / \mathrm{h}\end{array}$ \\
\hline \multirow{2}{*}{$\begin{array}{c}\text { A.2. } \\
\text { Segurança } \\
\text { Pública }\end{array}$} & $\begin{array}{l}\text { A.2.1. } \\
\text { lluminação }\end{array}$ & $\begin{array}{c}\text { Resultado da } \\
\text { avaliação = } \\
100\end{array}$ & $\begin{array}{l}\text { Resultado da } \\
\text { avaliação = } 90\end{array}$ & $\begin{array}{c}\text { Resultado da } \\
\text { avaliação = } 60\end{array}$ & $\begin{array}{l}\text { Resultado da } \\
\text { avaliação < } 60\end{array}$ \\
\hline & $\begin{array}{c}\text { A.2.2. } \\
\text { Eficiência } \\
\text { Energética }\end{array}$ & $\begin{array}{c}\text { Iluminação } \\
\text { com lâmpadas } \\
\text { de LED }\end{array}$ & & & $\begin{array}{l}\text { lluminação sem } \\
\text { lâmpadas LED }\end{array}$ \\
\hline
\end{tabular}




\begin{tabular}{|c|c|c|c|c|c|}
\hline & $\begin{array}{l}\text { A.2.3. Fluxo de } \\
\text { Pedestres } \\
\text { Diurno e } \\
\text { Noturno }\end{array}$ & $\begin{array}{l}\text { Uso/Fluxo de } \\
\text { pessoas nos } \\
\text { turnos diurno e } \\
\text { noturno em } \\
\text { todos os dias } \\
\text { da semana. }\end{array}$ & $\begin{array}{c}\text { Uso/Fluxo de } \\
\text { pessoas em um } \\
\text { dos turnos } \\
\text { (diurno ou } \\
\text { noturno) em } \\
\text { todos os dias } \\
\text { da semana. }\end{array}$ & $\begin{array}{c}\text { Uso/Fluxo de } \\
\text { pessoas em um } \\
\text { dos turnos } \\
\text { (diurno ou } \\
\text { noturno) } \\
\text { durante dias } \\
\text { úteis ou finais } \\
\text { de semana e } \\
\text { feriado. }\end{array}$ & $\begin{array}{l}\text { Ausência de } \\
\text { uso/fluxo de } \\
\text { pessoas em } \\
\text { diferentes } \\
\text { turnos e dias da } \\
\text { semana. }\end{array}$ \\
\hline & $\begin{array}{l}\text { A.2.4. Câmeras } \\
\text { de Segurança }\end{array}$ & Presença & N/A & N/A & Ausência \\
\hline \multirow{4}{*}{$\begin{array}{l}\text { A.3. } \\
\text { Proteção } \\
\text { Física }\end{array}$} & $\begin{array}{c}\text { A.3.1. } \\
\text { Localização } \\
\text { do Espaço } \\
\text { para Brincar } \\
\end{array}$ & $\begin{array}{l}\text { Localização } \\
\text { central e com } \\
\text { cercamento. }\end{array}$ & $\begin{array}{l}\text { Localização } \\
\text { central e sem } \\
\text { cercamento. }\end{array}$ & $\begin{array}{c}\text { Localização } \\
\text { próxima as vias } \\
\text { e com } \\
\text { cercamento. }\end{array}$ & \begin{tabular}{|c|} 
Localização \\
próxima as vias \\
e sem \\
cercamento. \\
\end{tabular} \\
\hline & $\begin{array}{l}\text { A.3.2. Material } \\
\text { do Piso da } \\
\text { Área Infantil }\end{array}$ & $\begin{array}{l}\text { Piso de } \\
\text { borracha }\end{array}$ & $\begin{array}{c}\text { Grama natural } \\
\text { ou sintética. } \\
\text { Lasca de } \\
\text { madeira ou } \\
\text { borracha } \\
\text { granulada }\end{array}$ & Areia & $\begin{array}{c}\text { Piso asfáltico ou } \\
\text { intertravado }\end{array}$ \\
\hline & $\begin{array}{c}\text { A.3.3. Material } \\
\text { dos Brinquedos } \\
\text { Infantis }\end{array}$ & $\begin{array}{c}\text { Principal } \\
\text { material: } \\
\text { plástico } \\
\text { rotomoldado } \\
\end{array}$ & $\begin{array}{c}\text { Principal } \\
\text { material: } \\
\text { madeira ou } \\
\text { emborrachado }\end{array}$ & $\begin{array}{l}\text { Principal } \\
\text { material: } \\
\text { concreto }\end{array}$ & $\begin{array}{c}\text { Principal } \\
\text { material: metal }\end{array}$ \\
\hline & $\begin{array}{c}\text { A.3.4. Estado } \\
\text { de } \\
\text { Conservação } \\
\text { dos Brinquedos }\end{array}$ & $\begin{array}{c}\text { Ótimo estado } \\
\text { de } \\
\text { conservação } \\
(100 \%)\end{array}$ & $\begin{array}{c}\text { Bom estado } \\
\text { conservado (70 } \\
\text { a } 99 \%)\end{array}$ & $\begin{array}{c}\text { Regular estado } \\
\text { de } \\
\text { conservação } \\
\text { (50 a 69\%) }\end{array}$ & $\begin{array}{l}\text { Estado de } \\
\text { conservação } \\
\text { ruim (<50\%) }\end{array}$ \\
\hline
\end{tabular}

Fonte: Autor (2019)

A avaliação do indicador "Travessias" foi realizada a partir da identificação dos pontos de travessias de pedestres. Com base nos requisitos de qualidade do Quadro 4, cada travessia recebeu uma pontuação de 0 a 100 a partir do somatório destes (Figura 2).

Quadro 4 - Requisitos do indicador travessias

\begin{tabular}{|l|l|}
\hline Nota & \multicolumn{1}{|c|}{ Requisito } \\
\hline+30 & $\begin{array}{l}\text { Há faixa de travessia de pedestres visível ou trata-se de via } \\
\text { com baixo volume de veículos motorizados (existe somente } \\
\text { uma faixa de circulação de veículos ou trata-se de via } \\
\text { compartilhada com os diferentes modos de transporte). }\end{array}$ \\
\hline+25 & $\begin{array}{l}\text { Há rampas com inclinação apropriada às cadeiras de rodas } \\
\text { no acesso à travessia de pedestres ou a travessia é no nível da } \\
\text { calçada. }\end{array}$ \\
\hline+15 & $\begin{array}{l}\text { Há piso tátil de alerta e direcional no acesso à travessia de } \\
\text { pedestres. }\end{array}$ \\
\hline+30 & $\begin{array}{l}\text { Com semáforos: A duração da fase "verde" para pedestres é } \\
\text { superior a 10 segundos e a duração da fase "vermelha" para } \\
\text { pedestres (tempo de ciclo) é inferior a 60 segundos. } \\
\text { Sem semáforos: Há áreas de espera de pedestres (ilhas de } \\
\text { refúgio ou canteiros centrais) para travessias com distância } \\
\text { superior a 2 faixas de circulação de automóveis consecutivas. }\end{array}$ \\
\hline
\end{tabular}




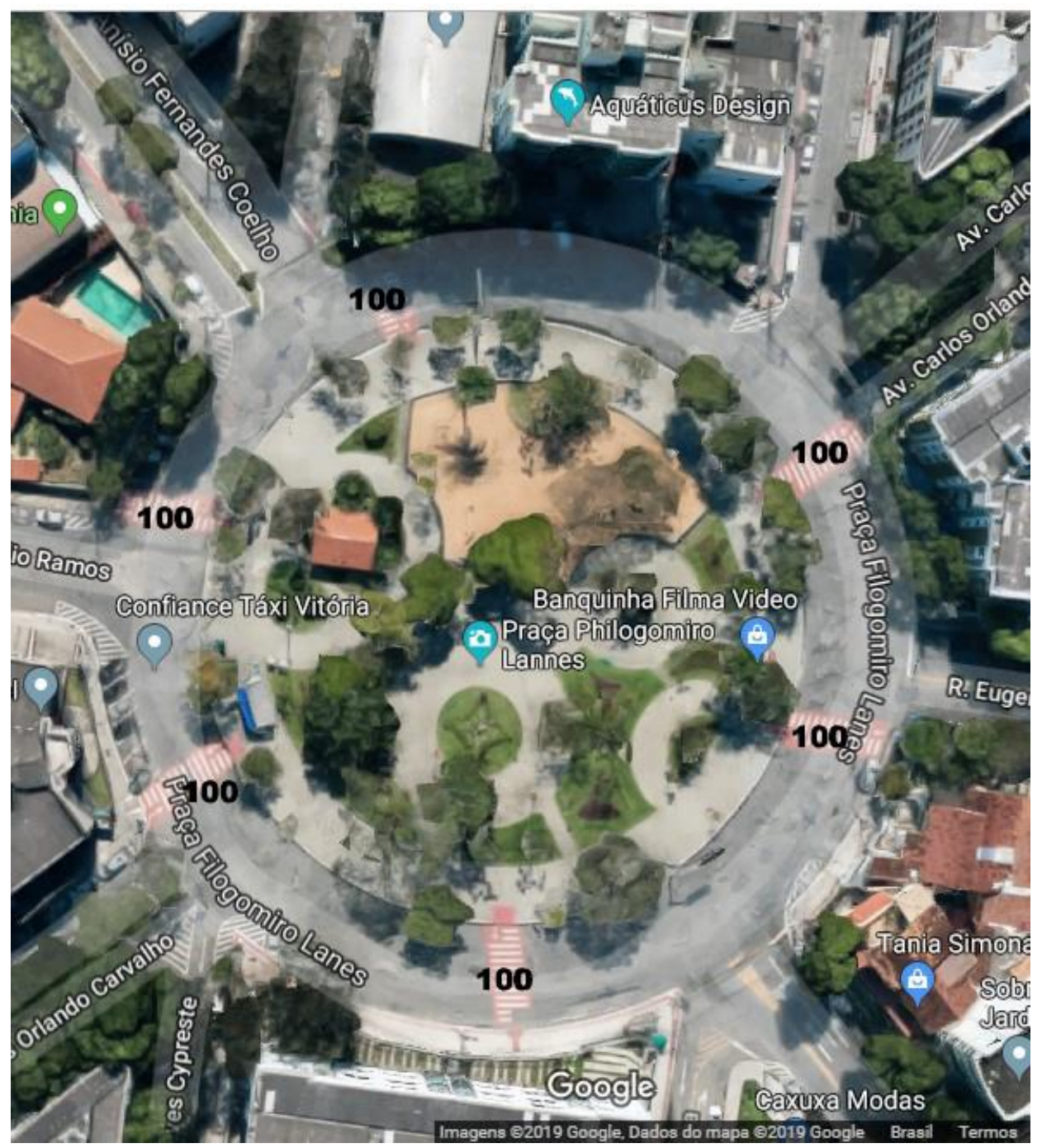

Figura 2 - Pontuação de cada travessia

Fonte: Adaptado do Google Maps (2019)

Assim como no indicador "Travessias", o parâmetro do indicador "lluminação" foi dado a partir do somatório dos requisitos de qualidade do Quadro 5, com base nos postes de iluminação existentes.

\begin{tabular}{|c|l|}
\hline \multicolumn{2}{l}{ Quadro 5 - Requisitos do indicador lluminação } \\
\hline Nota & $\begin{array}{l}\text { Requisito } \\
\text { Há pontos de iluminação voltados à rua (faixas de circulação } \\
\text { de veículos). }\end{array}$ \\
\hline+20 & $\begin{array}{l}\text { Há pontos de iluminação dedicados ao pedestre, iluminando } \\
\text { exclusivamente a praça. }\end{array}$ \\
\hline+40 & $\begin{array}{l}\text { Há pontos de iluminação nas extremidades do segmento, } \\
\text { iluminando a travessia. (nota +20 se houver em somente uma } \\
\text { extremidade). }\end{array}$ \\
\hline-10 & $\begin{array}{l}\text { Há obstruções de iluminação ocasionadas por árvores ou } \\
\text { lâmpadas quebradas. }\end{array}$ \\
\hline & \\
\hline
\end{tabular}

Fonte: Autor (2019) 


\section{APRESENTAÇÃO E ANÁLISE DOS RESULTADOS}

De acordo com a Lei $n^{\circ} 8.611 / 2014$ a Regional 9 compõe-se de seis bairros, sendo estes: Boa Vista, Jardim da Penha, Mata da Praia, Morada de Camburi, Pontal de Camburi e República (Figura 3).

A região detém a segunda maior população do Estado, é a sétima em área e densidade demográfica, apresentando, segundo dados do Instituto Brasileiro de Geografia e Estatística (IBGE), cerca de 48.000 habitantes, $3.665 \mathrm{~km}^{2} \mathrm{e}$ 13.140 habitantes por $\mathrm{km}^{2}$ (IBGE, 2010). A região é uma das mais urbanizadas do município, contendo 17.207 domicílios, 16.367 atividades econômicas e renda média de $\mathrm{R} \$ 2.737,84$ (IBGE, 2010).
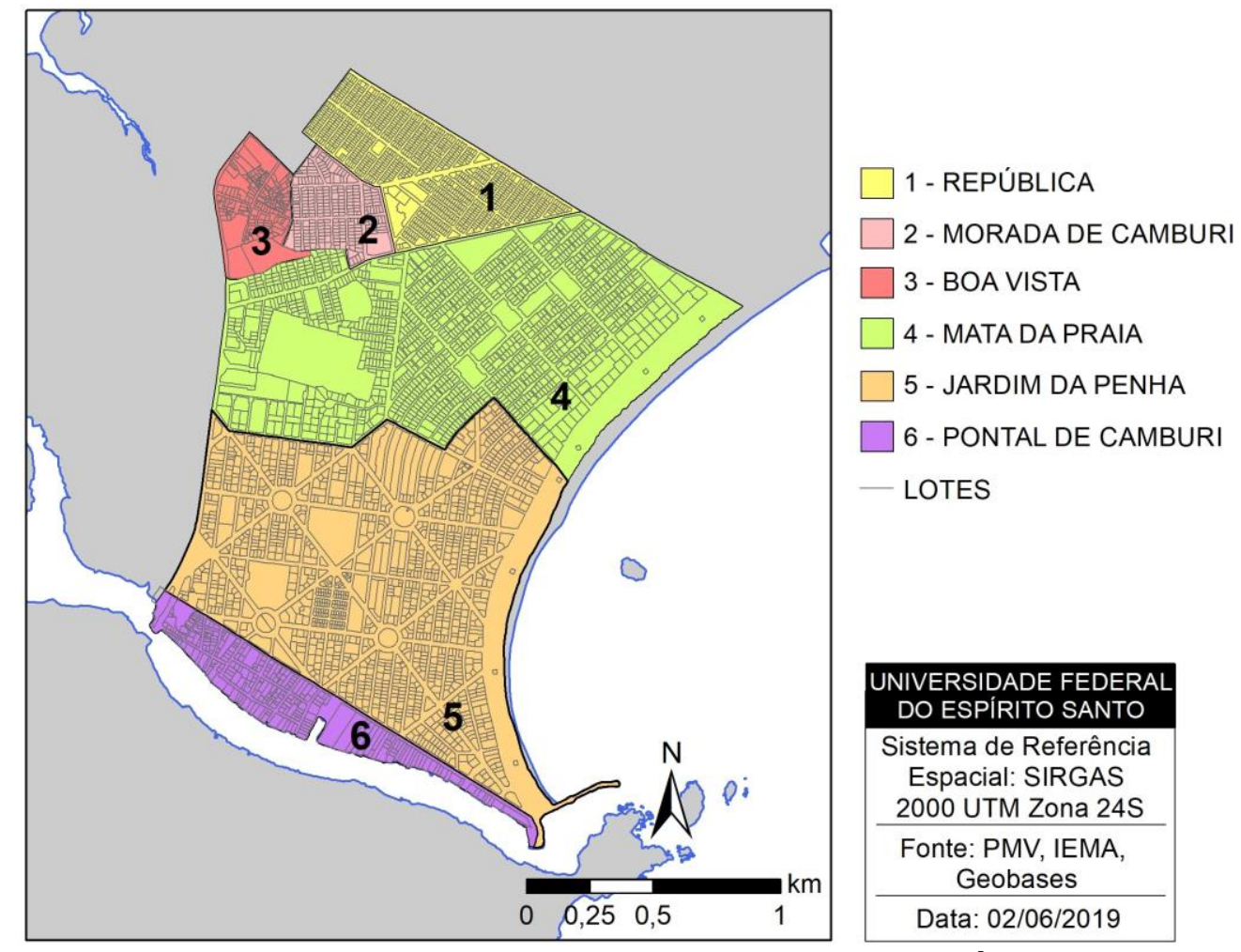

Figura 3 - Mapa da Regional 9 - Jardim da Penha Vitória (ES) Fonte: Autor (2019)

A Regional 9 é bastante heterogênea, apresentando bairros muito distintos com relação ao número de habitantes, atividades econômicas e renda média, como pode ser observado no Quadro 6. Dois bairros se destacam por deter significativos dados socioeconômicos dentro da regional, Mata da Praia e Jardim da Penha, estes abrigam dois importantes marcos da cidade, a Praia de Camburi e o Parque Pedra da Cebola, identificados também como espaços livres de uso público.

Quadro 6 - Dados socioeconômicos da Regional 9

\begin{tabular}{|c|c|c|c|c|}
\hline Bairro & Área $\left.\mathbf{( k m}^{\mathbf{2}}\right)$ & Habitantes & Atividades Econômicas & Renda Média \\
\hline Boa Vista & 0,14 & 1.183 & 122 & $\mathrm{R} \$ 1.035,54$ \\
\hline Jardim da Penha & 1,46 & 30.571 & 8.912 & $\mathrm{R} \$ 2.510,89$ \\
\hline Mata da Praia & 1,35 & 10.594 & 4.251 & $\mathrm{R} \$ 4.119,31$ \\
\hline
\end{tabular}




\begin{tabular}{|c|c|c|c|c|}
\hline Morada de Camburi & 0,13 & 1.164 & 1.380 & $\mathrm{R} \$ 2.649,64$ \\
\hline Pontal de Camburi & 0,23 & 889 & 514 & $\mathrm{R} \$ 1.498,52$ \\
\hline República & 0,34 & 3.760 & 2.078 & $\mathrm{R} \$ 1.556,77$ \\
\hline
\end{tabular}

Fonte: Autor a partir de IBGE(2010)

\subsection{Identificação dos espaços livres}

Dentre os espaços livres de uso público presentes na Regional 9 - Jardim da Penha, Vitória (ES), estão 2 parques urbanos, Parque Pedra da Cebola e Parque Pe. Alfonso Pastore, este último formado por 5 praças. Além destas, outras 8 integram a regional, totalizando 13 praças a serem analisadas (Quadro 7).

Quadro 7 - Lista de parques e praças

\begin{tabular}{|c|c|c|c|}
\hline Bairro & & Nome & Área \\
\hline \multirow{6}{*}{ Jardim da Penha } & \multicolumn{2}{|c|}{ Praça Anníbal Anthero Martins } & $4.332 \mathrm{~m}^{2}$ \\
\hline & \multicolumn{2}{|r|}{ Praça Antônio Stiba } & $1.507 \mathrm{~m}^{2}$ \\
\hline & \multicolumn{2}{|c|}{ Praça Conjunto dos Estados } & $600 \mathrm{~m}^{2}$ \\
\hline & \multicolumn{2}{|r|}{ Praça Philogomiro Lannes } & $4.370 \mathrm{~m}^{2}$ \\
\hline & \multicolumn{2}{|r|}{ Praça Regina Frigeri Furno } & $5.118 \mathrm{~m}^{2}$ \\
\hline & \multicolumn{2}{|r|}{ Praça Wolghano Neto } & $4.623 \mathrm{~m}^{2}$ \\
\hline \multirow{6}{*}{ Mata da Praia } & \multicolumn{2}{|c|}{ Parque Ítalo Batan Régis/ Parque Pedra da Cebola } & $100.005 \mathrm{~m}^{2}$ \\
\hline & \multirow{5}{*}{$\begin{array}{c}\text { Parque Padre } \\
\text { Alfonso } \\
\text { Pastore }\end{array}$} & Praça Antônio Jacob Saad & $7.845 \mathrm{~m}^{2}$ \\
\hline & & Praça Benedito Rodrigues da Cruz & $8.177 \mathrm{~m}^{2}$ \\
\hline & & Praça Jacob Suaid & $8.394 \mathrm{~m}^{2}$ \\
\hline & & $\begin{array}{c}\text { Praça Márcio Manuel de A. } \\
\text { Sarmento }\end{array}$ & $7.833 \mathrm{~m}^{2}$ \\
\hline & & Praça Marien Calixte & $8.092 \mathrm{~m}^{2}$ \\
\hline \multirow{2}{*}{ República } & \multicolumn{2}{|c|}{ Praça Gabriel Muniz Vianna } & $593 \mathrm{~m}^{2}$ \\
\hline & \multicolumn{2}{|r|}{ Praça Therezinha Grecchi } & $4047 \mathrm{~m}^{2}$ \\
\hline \multicolumn{4}{|c|}{ Obs: Medidas aproximadas } \\
\hline
\end{tabular}

Fonte: Autor (2019)

Observa-se no Quadro 7 e na Figura 4 que apenas três bairros da regional analisada possuem praças ou parques, são: República (1), Mata da Praia (4) e Jardim da Penha (5). Por outro lado, considerado o raio de abrangência, conclui-se que praticamente toda a regional é atendida por praças e/ou parques, apesar de Morada de Camburi (2), Boa Vista (3) e Pontal de Camburi (6) não possuírem espaços de uso público com áreas superiores a $450 \mathrm{~m}^{2}$. 


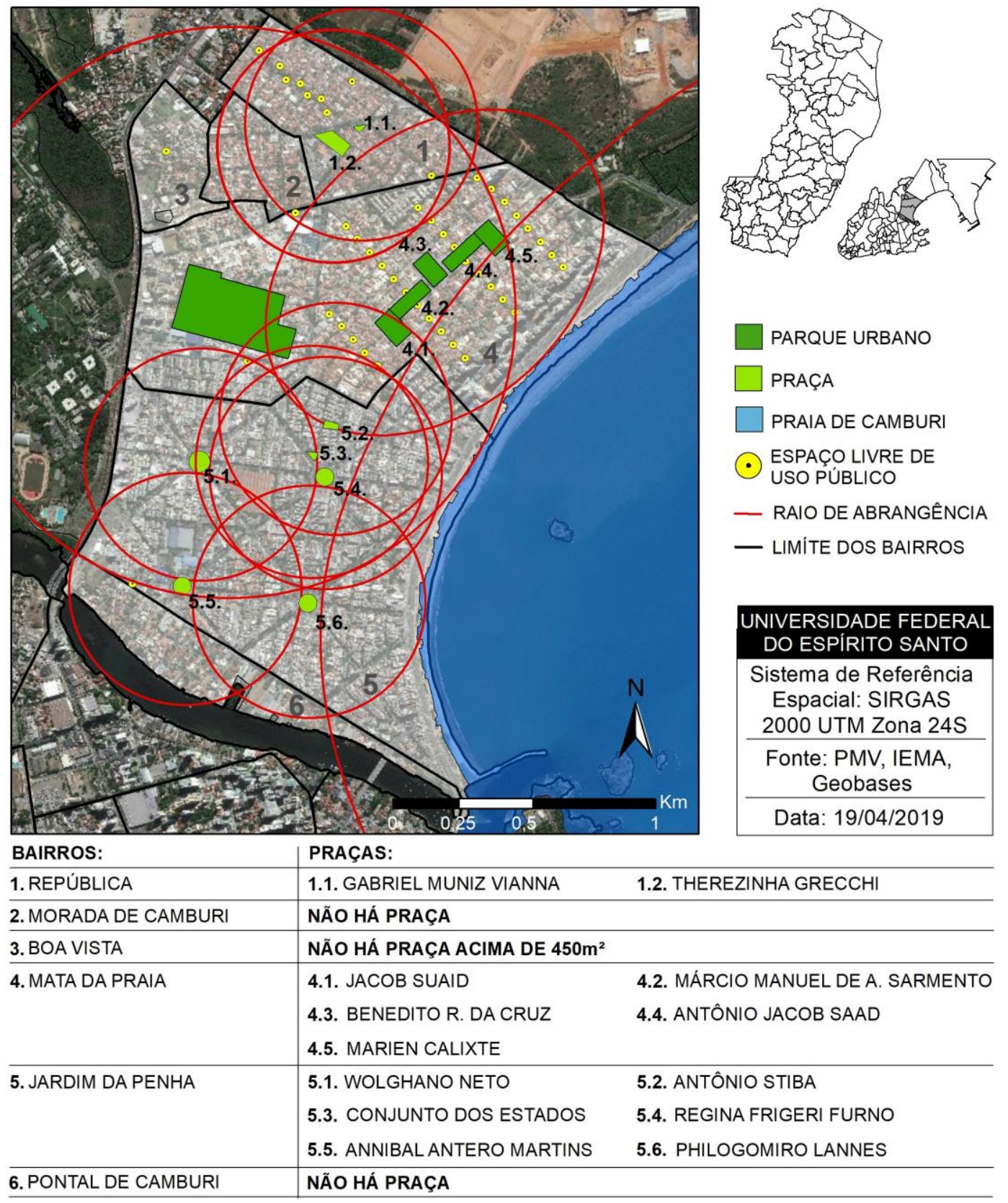

Figura 4 - Identificação dos espaços livres da Regional 9 - Jardim da Penha Vitória (ES) Fonte: Autor (2019)

A Regional 9 - Jardim da Penha possui dois parques urbanos, o Parque Pedra da Cebola, e o Parque Padre Alfonso Pastore, este formado por 5 praças. Foi adotado o raio de 1.000 metros para o Parque Pedra da Cebola e de 400 metros para cada uma das praças que formam o Parque Padre Alfonso Pastore, pois apesar de ser considerado um Parque Urbano, sua abrangência é equivalente à unidade de suas praças num raio de 400 metros. Devido a essa característica, o Parque Padre Alfonso Pastore foi analisado em função de cada praça.

\subsection{Aplicação dos indicadores}

Aplicando a metodologia à categoria de Proteção e Segurança, obtiveram-se os resultados apresentados no Quadro 8. 
Quadro 8 - Resultado da Avaliação

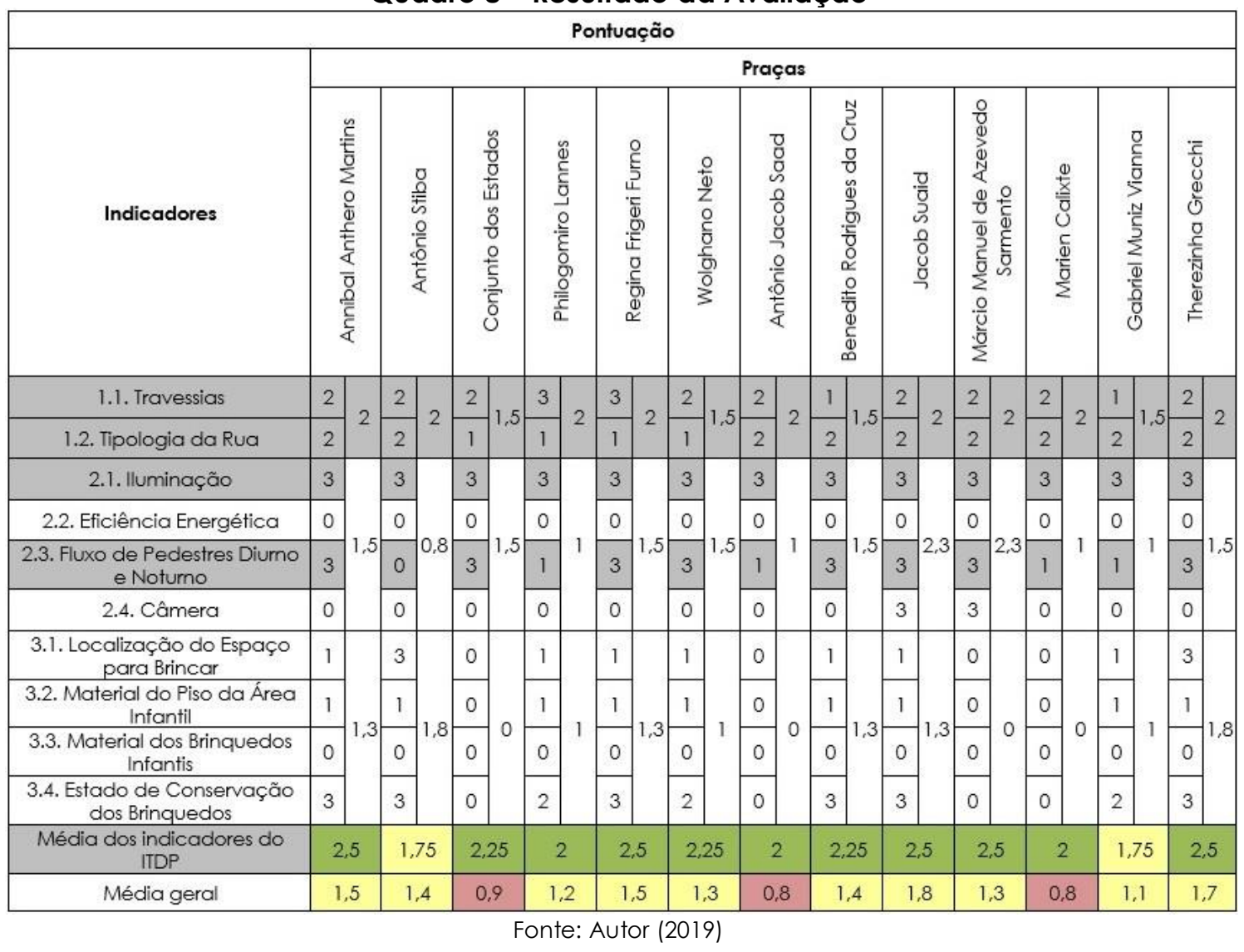

Analisando as pontuações para os indicadores da categoria "Proteção e Segurança", observa-se no Quadro 8 que as praças foram bem avaliadas, alcançando resultados "bom" (verde) e suficiente" (amarelo). Entretanto a média geral e a média dos indicadores do ITDP se destoam consideravelmente, com três praças apresentando resultados "insuficientes" (vermelho) na média geral, enquanto possuem resultado "bom" (verde) na média dos indicadores do ITDP.

Os indicadores Eficiência energética, Câmera e Material dos brinquedos foram os maiores responsáveis pela diferença entre as duas médias apresentadas, pois esses indicadores foram mal avaliados na maioria das praças. Tais resultados demonstram a pouca atenção na escolha do tipo de iluminação e do material dos brinquedos infantis, além de subestimar o vídeo monitoramento como requisito de segurança.

O vídeo monitoramento como ferramenta de segurança, avaliado pelo indicador Câmera, foi identificado em um único ponto no bairro Mata da Praia, suficiente para monitorar as praças Jacob Suaid e Márcio Manuel de Azevedo Sarmento. Entretanto. Por outro lado, foi identificado guarita nas praças Benedito Rodrigues da Cruz e Regina Frigeri Furno, além da presença de guarda regular no Centro de Educação Ambiental da Praça Antônio Jacob Saad. Vale considerar, portanto, que apesar da presença de guardas não anularem a necessidade do monitoramento eles aumentam a sensação de segurança no local. 


\section{CONSIDERAÇÕES FINAIS}

Para a avaliação da qualidade de praças, foram selecionados indicadores com base no Índice de Caminhabilidade elaborado pelo ITDP. Os estudos possibilitaram a compreensão da necessidade de adaptações para o objeto de estudo, e assim foram selecionadas e organizadas em 4 categorias, 11 atributos e 36 indicadores.

Os resultados dos indicadores da categoria "Proteção e Segurança" para avaliação das praças da Regional 9 - Jardim da Penha, Vitória (ES), indicam que 0 acréscimo de 5 indicadores, além dos adaptados do iCam, foi importante para uma avaliação mais abrangente da categoria, uma vez observadas as médias do ITDP e geral.

Os resultados indicam que a Regional 9 é bem atendida pelas praças, no entanto, problemas como materiais dos brinquedos, eficiência energética e monitoramento por câmera se mostraram frequentes. Os resultados foram consideravelmente uniformes e demonstram que a prefeitura municipal mantém certo padrão no planejamento urbano dos espaços públicos da regional.

\section{AGRADECIMENTOS}

Ao CNPq e à CAPES, pelo apoio recebido.

\section{REFERÊNCIAS}

ITDP. Índice de Caminhabilidade. Ferramenta, Versão 2.0. Instituto de Políticas de Transporte e Desenvolvimento. Rio de Janeiro, 2018.

BOVO, M.C.; AMORIM, M.T. Áreas Verdes Urbanas, a Imagem, o Mito e a Realidade: um estudo de caso sobre a cidade de Maringá/PR/BR. Revista Formação, v.1, n.16, p.60-69, 2009.

BUCCHERI FILHO, A.T.; NUCCl, J.C. Open spaces, green areas and tree canopy coverage in the Alto da XV district, Curitiba/PR. Revista do Departamento de Geografia, n. 18, 2006. p. 48-59.

CAVALHEIRO, F. et al. Proposição de Terminologia para o Verde Urbano.

Boletim Informativo da Sociedade Brasileira de arborização urbana. SBAU: Ano VII, Rio de Janeiro, 1999.

CONDE, K.; ALVAREZ, C.E.; BRAGANÇA, L. Proposta de critérios e indicadores de avaliação de sustentabilidade urbana para países latino-americanos. In: EUroELECS 2019. III Encontro Latinoamericano Y Europeo sobre Edificaciones y Comunidades Sostenibles. Argentina, Libro de Actas... Santa Fe, Argentina, Maio 22-25, 2019 p.1412-1424.

HANNES, Evy. Espaços abertos e espaços livres: um estudo de tipologias.

Paisagem e Ambiente: Ensaios - N. 37 - São Paulo, 2016. p.121 - 144.

HEEMANN, Jenifer; SANTIAGO, Caiuby. Guia do espaço público para inspirar e transformar. Mountain View (CA), USA, 2015.

IBGE. Instituto Brasileiro de Geografia e Estatística. CENSO DEMOGRÁFICO 2010. Características da população e dos domicílios: resultados do universo. Rio de Janeiro: IBGE, 2010. 
JACOB, J. The Death and Life of Great American Cities. Estados Unidos, 1961. KLIASS, Rosa Grená. Parques Urbanos de São Paulo. São Paulo: Pini, 1993. LIMA, A. et al. Problemas de Utilização na Conceituação do Termos como Espaços Livres, Áreas Verdes e Correlatos. In: II CONGRESSO BRASILEIRO DE ARBORIZAÇÃO URBANA. São Luís, Anais... São Luís, 1994, p. 539-553.

FERREIRA, C.C.M.; PAULA, I.F.M. Análise dos espaços de uso público da cidade de juiz de fora $(\mathrm{mg})$ com base no conceito de áreas verdes. Revista on-line -

CAMINHOS DE GEOGRAFIA. Uberlândia, 2014, v.15,n.49, p. 160-174. 